\title{
Stochastic modelling and lifecycle performance assessment of bond strength of corroded reinforcement in concrete
}

\author{
Hua-Peng Chen* and Jaya Nepal \\ School of Engineering, University of Greenwich, Chatham Maritime, Kent, ME4 4TB, UK \\ (Received, Revised, Accepted)
}

\begin{abstract}
Life cycle performance of corrosion affected RC structures is an important and challenging issue for effective infrastructure management. The accurate condition assessment of corroded RC structures mainly depends on the effective evaluation of deterioration occurring in the structures. Structural performance deterioration caused by reinforcement corrosion is a complex phenomenon which is generally uncertain and non-decreasing. Therefore, a stochastic modelling such as the gamma process can be an effective tool to consider the temporal uncertainty associated with performance deterioration. This paper presents a time-dependent reliability analysis of corrosion affected RC structures associated bond strength degradation. Initially, an analytical model to evaluate cracking in the concrete cover and the associated loss of bond between the corroded steel and the surrounding cracked concrete is developed. The analytical results of cover surface cracking and bond strength deterioration are examined by experimental data available. Then the verified analytical results are used for the stochastic deterioration modelling, presented here as gamma process. The application of the proposed approach is illustrated with a numerical example. The results from the illustrative example show that the proposed approach is capable of assessing performance of the bond strength of concrete structures affected by reinforcement corrosion during their lifecycle.
\end{abstract}

Keywords: reinforcement corrosion; concrete cracking; bond strength; performance deterioration; gamma process; reliability analysis

\section{Introduction}

The performance of the reinforced concrete (RC) structures exposed to aggressive environments such as motorway bridges, car parks and marine structures is often seriously affected by corrosion in reinforcement. Corrosion initiates when the aggressive agents reach the reinforcement due to concrete carbonation or chloride attack. The corrosion products formed during corrosion process are expansive in nature, which causes two to six times volume increase as compared with the original steel (Pantazopoulou and Papoulia 2001). This volume increase creates expansive force at the rebar surface and subsequently produces radial splitting cracks in the surrounding concrete. Furthermore, the loss of cross-sectional area of the rebar and the loss of bond strength between corroded steel and concrete directly affect the flexural strength of the RC structure (Bhargava et al. 2007a, Xia et al. 2012, Chen and Bicanic 2010, Shetty et al. 2014, Fan et

*Corresponding author, Professor, E-mail: h.chen@gre.ac.uk 


\section{Hua-Peng Chen and Jaya Nepal}

al. 2014). Therefore, they cannot perform in the way that they are designed for.

Bond strength acting at the rebar surface is the interaction mechanism that enables the force transfer between rebar and the surrounding concrete. Hence it maintains the composite action in $\mathrm{RC}$ structures. When composite action is disrupted, load carrying capacity is also affected (Rodriguez et al. 1994, Coronelli 2002, Huang and Chen 2013, Nepal and Chen 2014). This in turn changes the overall behavior of the RC structures. Hence for the satisfactory performance of the $\mathrm{RC}$ structures adequate bond between rebar and surrounding concrete is essential.

Many experimental investigations have been undertaken during the last two decades regarding bond behavior of corroded reinforcement (Law et al. 2011). In general, these experimental investigations suggest that at low level of corrosion $(<1 \%)$ bond strength increases, and with further increase in corrosion bond strength decreases significantly. Loss up to $80-90 \%$ of the initial bond strength has also been observed for only about $5-7 \%$ of the corrosion level in concrete without transverse reinforcement (unconfined) (Rodriguez et al. 1994, Auyenga et al. 2000, Banba et al. 2014). On the other hand, confined concrete exhibits comparatively less amount of reduction in bond strength for the same level of corrosion, compared with unconfined case (Zhao et al. 2014). Similar results were observed from analytical and numerical studies carried out by Coronelli (2002), Lundgren (2002), Wang and Liu (2004) and Bhargava et al. (2007b). Few experimental investigations have also been carried out in order to evaluate the relationship between surface crack width and bond behavior of corroded deformed rebar (Al-Sulaimani et al. 1990, Rodriguez et al. 1994, Almusallam et al. 1996, Fischer et al. 2010, Law et al. 2011, Li and Yuan 2013, Banba et al. 2014). Some empirical relations have also been proposed to describe the influence of crack width on the bond strength of the corroded plain rebar based on the experimental results (Cairns et al. 2006). The summary of the published results on the bond strength behavior of the corroded deformed rebar with respect to surface crack width obtained from various reference literatures is presented in Fig. 1.

The results in Fig. 1 are obtained by plotting normalized residual bond strength ratio of ultimate bond strength of the corroded element $\left(T_{u b x}\right)$ to non-corroded element $\left(T_{u b o}\right)$ versus surface crack

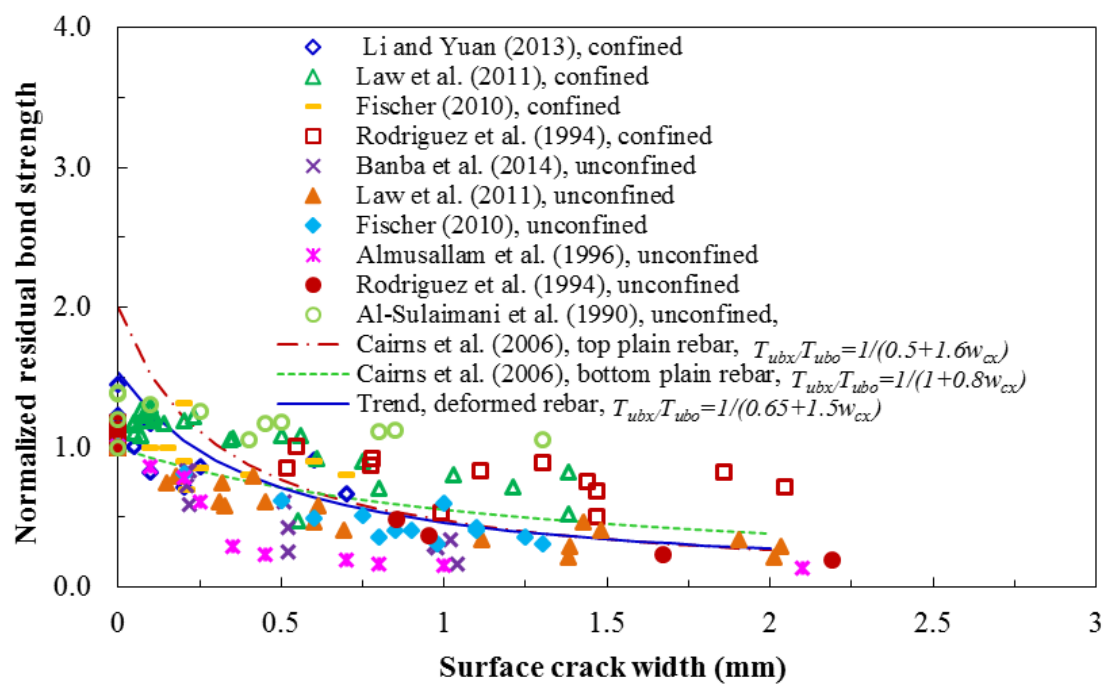

Fig. 1 Relation between normalized residual bond strength and corrosion induced surface crack width 
Stochastic modelling and lifecycle performance assessment of bond strength...

width $\left(w_{c x}\right)$, together with the results obtained from the empirical equations proposed by Cairns $e t$ al. (2006). In the case of plain rebar, bottom rebar in tension appears more vulnerable than the top rebar in compression. Significant scatter can be observed from these experimental investigations. A trend line for the results has been plotted, which indicates that an increase in crack width at the cover surface, leading to reduction in residual bond strength. Therefore, despite the scatter and inconsistencies between the quantitative reductions in the residual bond strength, Fig. 1 clearly shows that the residual bond strength of the corroded rebar rapidly deteriorates with an increase in cover surface crack width.

Research on the prediction of the life cycle performance of corroded RC structures associated with bond strength degradation is very limited. Stochastic modelling for bond strength deterioration has significant potential for assessing the condition and life cycle performance of the RC structures (Q) analysis of corroded RC structures during their life cycle is useful for providing optimum inspection and maintenance strategies. This can ultimately help in minimizing the future scheduled repair and rehabilitation costs for those structures or their degraded members in order to maintain the probability of failure below a predefined target value. In structural deterioration modelling, Markov chain method has been often used to model the deterioration of various structures. Due to its restrictive stationary assumptions about the time dependent deterioration rate, Markov chain method has been widely criticized (Frangopol et al. 2001). In this study, Gamma process model is more appropriate model for the stochastic deterioration modelling because of its ability to incorporate the temporal uncertainty associated with the evolution of deterioration (Van Noortwijk and Frangopol 2004, Noortwijk 2009, Chen and Alani 2013).

This paper presents a time-dependent reliability analysis of corrosion affected RC structures associated with the bond strength degradation. Analytical solutions are provided to evaluate the crack width at the cover surface and predict the corresponding loss of bond between the corroded steel and the surrounding cracked concrete. Then in order to model the progression of bond strength deterioration during the life cycle of the RC structure, a gamma process model is adopted here. The time-dependent reliability analysis is then applied to evaluate the probability of failure of the RC structure. In reliability analysis, structural failure is defined when its deterioration reaches the predefined allowable limit. Finally, a numerical example is used to demonstrate the applicability of the proposed approach.

\section{Structural deterioration}

Steel rebar embedded in the concrete is normally protected by a passive layer created by the high alkalinity of the concrete. This protective layer can be broken down due to the cover concrete carbonation or the chloride ingress from the environment. Once the passive layer is broken down, corrosion initiates. Reinforcement corrosion propagates significantly and shortens the service life of the structure. The expansive layer of the corrosion product at the steel concrete interface will cause surface cracking and subsequent spalling of the cover concrete due to the corroding steel. The effect of corrosion on the performance deterioration of the corroded RC structures during their whole service life is illustrated in Fig. 2. Three phases are considered in the process, i.e., crack initiation phase, crack propagation phase and residual life phase. The crack initiation phase starts from the time of construction and ends at the time when the corrosion induced cracking initiates at the interface between the steel rebar and the concrete cover. After cracking occurs at the concrete 
Hua-Peng Chen and Jaya Nepal

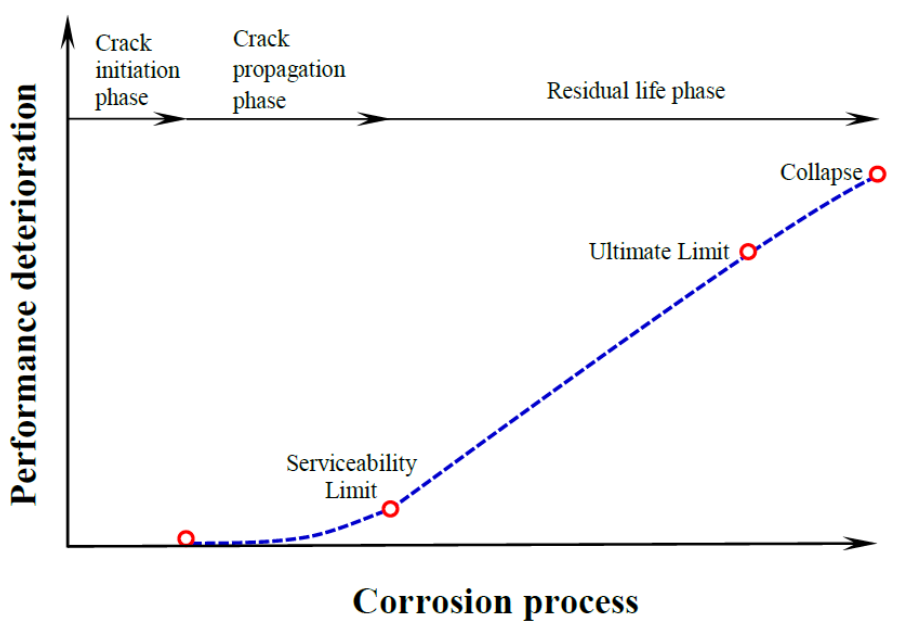

Fig. 2 Schematic representation of performance deterioration due to reinforcement corrosion in life cycle of RC structures

cover surface, the bond strength between the steel reinforcement and the surrounding concrete starts decreasing and the performance of the concrete structures deteriorates gradually. Due to further corrosion of steel rebar, cracking propagates and widens in the concrete cover and then reaches an unacceptable level. At this stage, the structures reach their serviceability limit state. The residual phase starts from the serviceability limit until reaching the ultimate limit stage, after which structures finally collapse.

\subsection{Reinforcement corrosion}

As shown in Fig. 2, crack propagation and residual life phases play the significant role in service life of RC structures exposed to aggressive environment. For the time-dependent reliability analysis of these structures, quantification of the damages associated with the propagation of the reinforcement corrosion is required. The corrosion induced damage may be caused by: i) loss of cross-sectional area of the rebar, ii) cracking in the concrete cover and iii) loss of residual strength of the structure. To measure the damages in servicing RC structures, only crack width in cover concrete may be measured without disturbing the functionality of the structure. For other types of damage destructive testing may be required and this may be practically impossible. Therefore, for the structures in service, non-destructive testing is typically required. Most of the non-destructive testing techniques used for the monitoring and evaluation of damages caused by corrosion are often based on the electrochemical measurements, the annual mean corrosion rate is estimated in terms of the corrosion current density, $i_{\text {corr }}$ (Val et al. 1998). The $i_{\text {corr }}$ can be transformed into the amount of metal loss by using the diffusion law related to the growth of expansive corrosion products (Pantazopoulou and Papoulia 2001). Reduction in cross-sectional area of steel rebar with time helps in quantifying the existing residual strength and predicting the future performance of the corrosion-damaged $\mathrm{RC}$ structures.

\subsection{Loss of cross-sectional area of the rebar}


Stochastic modelling and lifecycle performance assessment of bond strength...

In evaluation of the mass loss or the sectional loss of the corroded rebar in RC structures, reduction in rebar diameter $D_{b x}$ from the initial state $D_{b}$ is generally evaluated in terms of the attack penetration $x$ (pitting attack or homogeneous corrosion) as mentioned in Vidal et al. (2004)

$$
D_{b x}=D_{b}-\alpha_{p} x
$$

where $\alpha_{p}$ is attack penetration factor indicating localised corrosion at the earlier stage when $4<\alpha_{p}<8$ and homogeneous corrosion at later stage when $\alpha_{p}=2$. The associated corrosion level $X_{p}$ is defined as the ratio of the mass loss of corroded rebar $\Delta m_{s}$ to the original mass of the rebar $m_{o}$, namely

$$
X_{p}=\frac{\Delta m_{s}}{m_{o}}=\frac{\Delta A_{b}}{A_{b}}=1-\frac{D_{b x}^{2}}{D_{b}^{2}}
$$

where $\Delta A_{b}$ is the cross-sectional area associated with the mass loss of the corroded rebar and $A_{b}$ is the cross-sectional area of original rebar. Depending on the level of oxidation, corrosion product formed during the life cycle of the RC structures may have distinct characteristics with different relative volume and molecular weight ratio. The volume ratio $\gamma_{v o l}$ of the corrosion product formed to its parent metal generally lies between 1.8 and 6.4 , and corresponding molecular weight ratio $\gamma_{\text {mol }}$ ranges from 0.78 to 0.35 . The density of the rust product formed during corrosion process can be evaluated from $\rho_{r}=\rho_{s} / \gamma_{m o} l \gamma \sqrt{2}$ d its corresponding rust mass $m_{r}$ can be defined as $m_{r}=\Delta m_{s} / \gamma_{m o l}$ (Pantazopoulou and Papoulia 2001, Lundgren 2002). Thus, the volume of the rust product formed can be expressed as

$$
V_{r}=\gamma_{v o l} A_{b} X_{p}
$$

Then the corresponding volume increase per unit length of the rebar is given by $\Delta V=V_{r}-\Delta V_{s}$, in which $\Delta V_{s}$ is the volume loss of the corroded rebar. This increase in volume creates a radial displacement at the bond interface $u_{b x}$ and can be obtained from

$$
u_{b x}=\frac{\Delta V}{\pi D_{b}}=\frac{1}{4}\left(\gamma_{v o l}-1\right) D_{b} X_{p}
$$

The prescribed displacement $u_{b x}$ related to corrosion level will be considered as the boundary condition of the boundary-value problem for analysing concrete cracking process and predicting bond strength evolution. According to the study carried out by Zhang et al. (2010), in long-term natural corrosion process, at the beginning although corrosion appears as the localised but in later stage it appears as uniform corrosion. Hence in this paper corrosion has been considered as uniform, since bond strength typically deteriorates at later stage of reinforcement corrosion. Therefore, $u_{b x}$ is the axis symmetric radial displacement caused by uniform expansive corrosion product acting at the rebar surface.

\subsection{Cracking in concrete cover}

Due to the expansive nature of the corrosion product formed, radial and hoop stresses are developed at the surrounding concrete cover. When this hoop stress in concrete cover reaches the tensile strength of the concrete, it results in longitudinal cracking and eventually spalling of the concrete cover. The propagation of cracks in the concrete cover causes significant effect on the performance of the structure, as shown in Fig. 1. Before concrete cracking, intact concrete can be 


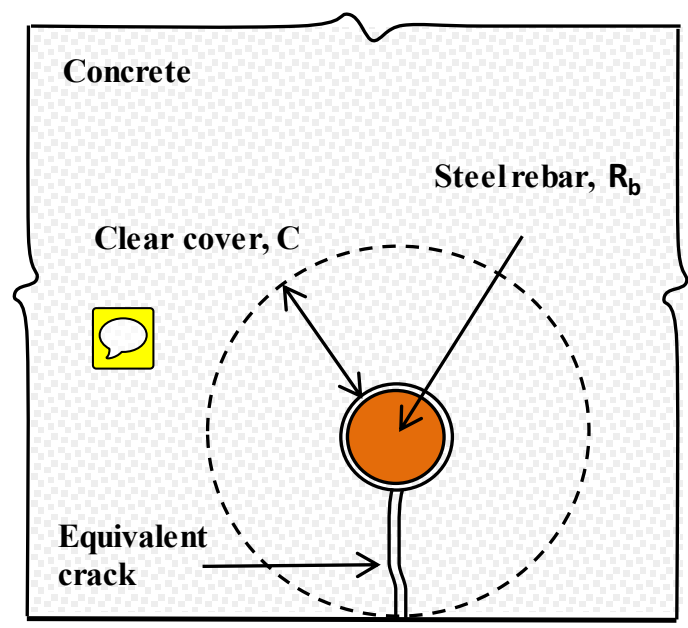

Fig. 3 Idealization of cover concrete as thick-walled cylinder model for predicting concrete crack development and residual strength evolution

treated as isotropic elastic materials. Therefore by considering governing equations and stress distribution obtained by thick walled cylinder model, corrosion level required for crack initiation at the rebar surface can be estimated (Chen and Alani 2013).

The concrete cracking process due to reinforcement corrosion has been investigated analytically by adopting the anisotropy of cracked concrete and thick walled cylinder model previously utilized by Chen and Xiao (2012) together with the concept of equivalent crack as utilized by Chen and Alani (2013). The schematic representation of thick walled cylinder model used in this paper is shown in Fig. 3, in which the concrete surrounding the reinforcing rebar is considered as thick walled cylinder with wall thickness equal to clear cover depth (C). When the concrete cover cracks, the concrete behaves as an anisotropic material. Therefore for the quantification of the cracks propagating in the concrete cover, cracks can be considered as cohesive in nature and residual tensile stress in the cracked concrete can be obtained by adopting bilinear stress softening law of cracked concrete as described in CEB-FIP (1990).

In the cohesive crack model, the stress transferred through the cohesive cracks is assumed to be a function of crack opening (softening curve), expressed as

$$
\begin{aligned}
& \text { Cover } \\
& \text { sur } R_{\mathbf{c}}
\end{aligned} f_{t}(a-b W)
$$

where $\sigma_{w}$ is the tensile stress acting across cohesive cracks; $f_{t}$ is the maximum tensile strength of concrete at onset of cracking; $W$ is the normalized crack width defined as $W=f_{t} w(r) / G_{f}$ in which $G_{f}$ is the fracture energy of the concrete; $w(r)$ is the actual crack width at any point $r$ between $R_{b}$ and $R_{c}$ as shown in Fig. 3. Coefficients $a$ and $b$ are the bilinear coefficients, depending on the precritical stage $\left(0 \leq W \leq W_{c r}\right)$ and post-critical stage $\left(W_{c r} \leq W \leq W_{u}\right)$ of crack width, as

$$
\begin{gathered}
a=\frac{1-\alpha}{W_{c r}} r \text { pre-critical stage } \\
a=\frac{\alpha_{b i} W_{u}}{W_{u}-W_{c r}}=\frac{\alpha_{b i}}{W_{u}-W_{c r} r^{r} \text { post }- \text { critical stage }}
\end{gathered}
$$


in which $\alpha_{b i}$ is coefficient of bilinear softening curve; $W_{c r}$ is normalized critical crack width and $W_{u}$ is ultimate cohesive crack width. The critical and ultimate cohesive crack widths can be determined from experiments for concrete. In the CEB-FIP (1990), the coefficient $\alpha_{b i}$ is given as $\alpha_{b i}=0.15 ; W_{c r}$ and $W_{u}$ can be evaluated from concrete strength, fracture energy and maximum aggregate size.

From the anisotropic property and the bilinear softening law of the cracked concrete, Chen and Xiao (2012) have given the expression for the normalized crack width at the rebar surface $\left(R_{b}\right)$ of the thick walled cylinder, as

$$
W_{b x}=\frac{1}{b\left(l_{o}-R_{b}\right)}\left(\frac{E}{f_{t}} u_{b x}-a R_{b}\right)
$$

where $l_{o}$ is the material constant given by $l_{o}=n_{c} l_{c h} / 2 \pi b$ in which $n_{c}$ is the number of cracks taken as 3 or 4 for thick walled cylinder model and $l_{c h}=E G_{f} / f_{t}^{2}$ is the characteristic length introduced by Hillerborg et al. (1976); $E=E_{c} /\left(1+\theta_{c}\right)$ is the effective modulus of elasticity of the concrete in which $E_{c}$ is the modulus of elasticity of concrete and $\theta_{c}$ is the creep coefficient; and $u_{b x}$ is the axis symmetric radial displacement at the rebar surface as described in Eq. (4).

Once cracks initiate at the bond interface, they propagates towards the cover surface $\left(R_{c}\right)$. By using the two boundary conditions of the boundary value problem i.e. the hoop stress at the concrete cover surface reaching the concrete tensile strength and normalized crack width at bond interface in Eq. (7), the corrosion level at the time to crack on the cover surface $X_{p}^{c}$ can be obtained from Chen and Xiao (2012)

$$
X_{p}^{c}=\frac{2}{\left(\gamma_{v o l}-1\right)} \frac{f_{t}}{E}\left\{1+(1+\vartheta) \frac{2 R_{c}}{D_{b}}\left(l_{o}^{c r}-R_{b}\right)\left(l_{o}^{c r}-R_{c}\right) \delta^{c r}\left(R_{c}, R_{b}\right)\right\}
$$

where $\vartheta$ is the Poisson's ratio of the concrete. $\delta\left(R_{c}, R_{b}\right)$ is crack factor denoted by $\delta^{c r}\left(R_{c}, R_{b}\right)$ and $\delta^{u}\left(R_{c}, R_{b}\right)$ in pre-critical stage and post-critical stage of the cracking respectively, given by

$$
\begin{gathered}
\delta^{c r}\left(R_{c}, R_{b}\right)=\frac{R_{c}-R_{b}}{l_{0}^{c r}\left(l_{0}^{c r}-R_{c}\right)\left(l_{0}^{c r}-R_{b}\right)}+\frac{1}{\left(l_{0}^{c r}\right)^{2}} \ln \frac{R_{c}}{R_{b}} \frac{\left|l_{0}^{c r}-R_{b}\right|}{\left|l_{0}^{c r}-R_{c}\right|} \\
\delta^{u}\left(R_{c}, R_{b}\right)=\frac{R_{c}-R_{b}}{l_{0}^{u}\left(l_{0}^{u}-R_{c}\right)\left(l_{0}^{u}-R_{b}\right)}+\frac{1}{\left(l_{0}^{u}\right)^{2}} \ln \frac{R_{c}}{R_{b}} \frac{\left|l_{0}^{u}-R_{b}\right|}{\left|l_{0}^{u}-R_{c}\right|}
\end{gathered}
$$

in which $l_{o}^{c r}$ and $l_{o}^{u}$ are the aforementioned material constants for pre-critical stage and postcritical stage cracking of the concrete cover. By considering free surface condition at the cover surface and ignoring the Poisson's effect associated with the hoop strain of the completely cracked concrete, the normalized crack width on the concrete cover surface $W_{c x}$ can be obtained from Chen and Xiao (2012), expressed here as

$$
W_{c x}=\frac{W_{b x}-\frac{a}{b}\left\{R_{c}\left(l_{o}-R_{c}\right) \cdot \delta\left(R_{c}, R_{b}\right)\right\}}{1-R_{c}\left(l_{o}-R_{c}\right) \cdot \delta\left(R_{c}, R_{b}\right)}
$$

In cohesive crack model the process of concrete cracking continues until they reach their 
Hua-Peng Chen and Jaya Nepal

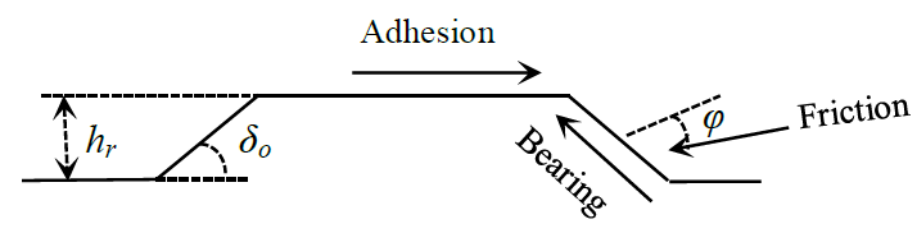

Fig. 4 Bond mechanisms for deformed reinforcing rebar

ultimate cohesive value $W_{u}$ (Chen and Xiao 2012, Chen and Alani 2013). Therefore, the corrosion level $X_{p}^{u}$ at which the equivalent crack in the concrete cover reaches its ultimate cohesive value can be obtained from Eq. (7) and Eq. (4), expressed here as

$$
X_{p}{ }^{u}=\frac{2}{\pi\left(\gamma_{v o l}-1\right)} \frac{f_{t}}{E} \frac{n_{c} l_{c h}}{D_{b}} W_{u}
$$

At this stage due to the widening of the crack opening, the residual strength and the corrosion stress acting at the rebar surface become negligible. Hence, in life cycle analysis this stage indicates the significant changes in resistance of RC structures.

\subsection{Bond strength deterioration}

Ultimate bond strength of deformed rebars mainly depends on three factors: chemical adhesion between the rebar and surrounding concrete; frictional force at the bond interface and mechanical interlocking of the ribs against the concrete surface (Cairns and Abdullah 1996). The schematic representation of the bond mechanism of typical deformed rebar is shown in Fig. 4. Reinforcement corrosion affects the bond properties between the rebar and the surrounding concrete by changing the shape and angle of the ribs of the deformed rebar. Corrosion also influences the mechanical interlocking between rebar and the surrounding concrete by reducing adhesion and frictional force due to the accumulation of corrosion products. Moreover reinforcement corrosion can also reduces the confinement action between concrete and steel by creating cracks in the concrete. With further progress of corrosion, cracking in the concrete cover continues widening, which simultaneously decreases the confinement stress and consequently the bond strength (Coronelli 2002, Wang and Liu 2004). Therefore corrosion in reinforcement threatens all these factors required for good bonding condition of the RC structures.

Efficient and reliable force transfer between the reinforcement and concrete is the fundamental requirement for an effective performance of the RC structures. Insufficient bond can lead to a significant reduction in the load carrying capacity and stiffness of the structure, which could directly affect on serviceability and ultimate strength of the RC structures (Bhargava et al. 2007b). Hence the evaluation of bond strength degradation is essential for the condition assessment of the corroded RC structures.

To consider these effects on the bond behavior of the corroded deformed rebar, Coronelli (2002) modified the analytical model proposed by Cairns and Abdullah (1996) for intact rebar. According to Coronelli (2002), the ultimate bond strength $\left(T_{u b x}\right)$ related to corrosion level can be evaluated as the sum of three stresses acting at the bond interface, i.e., adhesion stress $\left(T_{a d x}\right)$, confinement stress $\left(T_{c n f x}\right)$ and corrosion stress $\left(T_{\text {corr } x}\right)$, expressed here as

$$
T_{u b x}=T_{a d x}+T_{c n f x}+T_{\text {corr } x}
$$


Stochastic modelling and lifecycle performance assessment of bond strength...

The adhesion stress acting between rebar and concrete is related to interface cohesion, defined as non-splitting component associated with the friction and adhesion stress acting on inclined rib faces, is given by Coronelli (2002) as a function of corrosion level

$$
T_{a d x}=\frac{\Omega A_{r x} f_{c o h x}\left\{\cot \delta_{o}+\tan \left(\delta_{o}+\varphi\right)\right\}}{\pi D_{b x} S_{r}}
$$

where the number of stirrups provided; $A_{r x}=\pi D_{b x} h_{r x}$ is the reduced rib area in plane at right angle to rebar axis and $h_{r x}=0.07 D_{b x}$ is the reduced rib height of the rebar due to corrosion; $f_{c o h x}=2-$ $10\left(x-x_{c}\right)$ is the adhesion strength coefficient in which $x_{c}$ is the attack penetration or the corrosion depth corresponding to the through cracking of the concrete cover, and can be obtained once $X_{p}^{c}$ is known; $\tan \left(\delta_{o}+\varphi\right)$ can be estimated from 1.57-0.785x (Coronelli and Gambarova 2000) in which $\delta_{o}$ is the orientation of the rib usually taken as $45^{\circ}$ and $\varphi$ is the angle of friction between steel and concrete as shown in Fig. 4; and $S_{r}=0.6 D_{b}$ is the rib spacing (Wang and Liu 2004).

The confinement stress is given by

$$
T_{\text {cnfx }}=k_{\text {cnfx }} P_{\text {cnfx }}
$$

where $k_{c n f x}$ is the coefficient of confinement stress evaluated from $k_{c n f x}=n_{s t} C_{r} \tan \left(\delta_{o}+\varphi\right) / \pi$ in which $C_{r}$ is the shape factor constant taken as 0.8 for crescent shape rebar. In unconfined concrete structure $P_{c n f x}$ is only provided by the cracked concrete $\left(P_{c n f x, c}\right)$. But in the case of confined concrete, the confinement stress $P_{c n f x}$ is the total contribution of cracked concrete and the stirrup $\left(P_{c n f x, s t}\right)$. By adopting the properties of the thick walled cylinder model with cohesive cracks as described in Fig. 2, Nepal et al. (2013) has modified the expression of confinement stress given by Giuriani et al. (1991), expressed here as

$$
\begin{gathered}
P_{c n f x, c}=\left(\frac{2 C}{D_{b x}}\right) \times f_{t} \frac{D_{a}\left(w_{u}-w_{b x}\right)}{w_{u}\left(D_{a}+k_{c} w_{b x}\right)} \\
P_{c n f x, \mathrm{st}}=\left(\frac{n_{s t} A_{s t}}{D_{b x} S_{s t}}\right) \times E_{s t} \sqrt{\frac{a_{2} w_{b x}{ }^{2}}{\alpha_{s t}{ }^{2} D_{s t}{ }^{2}}+\frac{a_{1} w_{b x}}{\alpha_{s t} D_{s t}}+a_{o}}
\end{gathered}
$$

where $w_{b x}=G_{f} W_{b x} / f_{t}$ is actual crack width at the rebar surface corresponding to corrosion level; $k_{c}$ is the constant taken as 167 , is the cross-section area of stirrup leg with diameter of $D_{s t} ; S_{s t}$ is the spacing of stirrup; $E_{s t}$ is the modulus of elasticity of steel; $\alpha_{s t}$ is the shape factor of stirrup taken as 2; $a_{2}, a_{1}$ and $a_{0}$ are coefficients related to the trilateral local bond-slip law of the stirrup (Giuriani et al. 1991). From Eq. (15b) it is clear that the confinement stress provided by the cracked concrete depends on crack width at the rebar surface $\left(w_{b x}\right)$. Therefore, with increases of $w_{b x}$ the confinement stress provided by the cracked concrete decreases and ultimately becomes negligible when crack reaches its ultimate cohesive value $\left(w_{u}\right)$.

The bond strength contributed by the corrosion pressure is given by

$$
T_{\text {corrx }}=\mu_{x} P_{\text {corr } x}
$$

in which $\mu_{x}$ is the coefficient of the friction between the corroded rebar and cracked concrete defined as $0.37-0.26\left(x-x_{c}\right)$ and $P_{\text {corrx }}$ is the corrosion pressure or the radial pressure acting at the bond interface due to the accumulation of the corrosion product at the rebar surface. The corrosion 
pressure acting at bond interface can be evaluated from Chen and Xiao (2012)

$$
P_{\text {corrx }}=\frac{f_{t}}{1-\vartheta^{2}}\left\{\left(1+\vartheta \sqrt{\beta_{b x}}\right)\left(a-b W_{b x}\right)+\frac{\xi_{\text {corr }}}{\left(l_{o}-R_{b}\right)} \frac{b}{R_{b}}+\vartheta \sqrt{\beta_{b x}} b l_{o} \frac{W_{b x}}{R_{b}}\right\}
$$

where $\xi_{\text {corr }}$ is the corrosion factor given by $\xi_{\text {corr }}=-W_{b x} / \delta\left(R_{c}, R_{b}\right)$ before through cracking and $\xi_{\text {corr }}$ $=\left(W_{c x}-W_{b x}\right) / \delta\left(R_{c}, R_{b}\right)$ after through cracking of the concrete cover and $\beta_{b x}$ is the stiffness reduction factor associated with the cracked concrete, given by

$$
\beta_{b x}=\frac{1}{1+\left\{\frac{b l_{o} W_{b x}}{\left(a-b W_{b x}\right) R_{b}}\right\}}
$$

\section{Stochastic deterioration modelling}

The structural reliability of the corrosion affected RC structures mainly depends on the history of the two parameters: deterioration and the corresponding response of the structures. Both of these parameters are time-dependent in nature, hence the reliability of these structures is related to time. Reinforcement corrosion is a complex process, therefore there is possibility of high degree of uncertainties associated with both corrosion induced deterioration and its effect on the life-cycle performance of these structures. The uncertainties associated with the deterioration and the corresponding structural response can be dealt with as a stochastic process. Therefore timedependent structural reliability analysis based on the stochastic approach could be helpful in evaluating the existing condition and predicting the future performance of these structures suffering from reinforcement corrosion. The existing studies in the field of performance assessment of the corroded $\mathrm{RC}$ structures have shown that approximately $2-4 \%$ area reduction in rebar could cause approximately $0.3 \mathrm{~mm}$ of cracking at the cover surface (Alonso et al. 1998, Vidal et al. 2004, Xia et al. 2012). This corresponds to approximately $60-80 \%$ reduction in initial bond strength value of unconfined concrete (Rodriguez et al. 1994, Almusallam et al. 1996). This bond strength deterioration significantly changes the overall behavior of the RC structures. Hence in this study, probability of failure of the corroded $\mathrm{RC}$ structure is evaluated by considering the bond strength deterioration at the steel concrete interface together with the cracking at the cover surface.

In time-dependent reliability analysis of corrosion affected RC structures, the structural probability of failure $\left(P_{f}\right)$ during the life cycle of the structure undergoing deterioration can be defined as the stage at which the structural resistance or its corresponding deterioration reaches the intended threshold limit. The threshold limits can be chosen by using various maximum allowable limits such as acceptable crack width limit for the serviceability limit state and strength loss of the structure for the ultimate limit state. This predefined limit sate may vary in accordance with the requirement of the RC structures concerned. Thus, the probability of the corrosion affected RC structure to fail during their life time $(t)$ is given by

$$
P_{f}(t)=P_{r}[S(t) \geq L]
$$

where $L$ is the threshold limit or the maximum allowable limit of the structural deterioration and 
$S(t)$ is the structural action.

Cracking in concrete cover is the time-dependent in nature and is an important parameter which helps in condition monitoring of RC structures. Hence, it is always beneficial to evaluate the effect of concrete cover cracking on the residual bond strength and its effect on structural reliability of corrosion damaged RC structures. Therefore in this study, time-dependent reliability analysis is evaluated in terms of probability of failure of the corroded RC structures as a function of crack width. Here the bond strength deterioration associated with the corrosion induced cracking at the concrete cover surface $J_{b}\left(w_{c x}\right)$ is defined as

$$
J_{b}\left(w_{c x}\right)=\frac{T_{u b o}\left(w_{c x}\right)-T_{u b x}\left(w_{c x}\right)}{T_{u b o}\left(w_{c x}\right)}
$$

where $T_{u b o}\left(w_{c x}\right)$ and $T_{u b x}\left(w_{c x}\right)$ are the residual bond strength related with the onset of cracking and the further cracking at the concrete cover surface until reaching its ultimate cohesive value respectively.

From Fig. 1 it is clear that after cracking in the concrete cover surface, the bond strength deterioration due to reinforcement corrosion is continuous and non-negative. Therefore from the definition of gamma process (Van Noortwijk and Frangopol 2004, Chen and Alani 2012), the gamma process is suitable for the stochastic modelling of bond strength deterioration in corrosion affected RC structures during their life cycle. In gamma process deterioration model, the cumulative bond strength deterioration $\left(J_{b}\right)$ is a random quantity, and has the gamma distribution with the shape parameter $\eta\left(w_{c x}\right) \succ 0$ and scale parameter $\lambda \succ 0$. The probability density function of bond strength deterioration $\left(J_{b}\right)$ at crack width $w_{c x} \succ 0$ can be expressed as

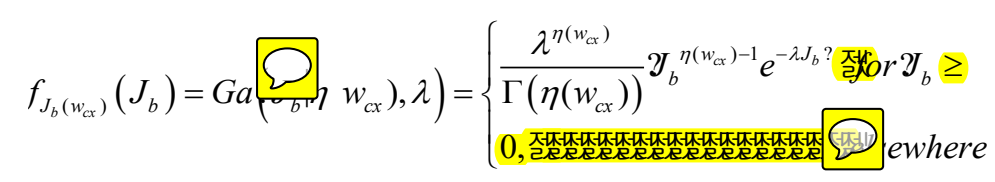

where $\Gamma\left(\eta\left(w_{c x}\right)\right)=\int_{0}^{\infty} v^{\eta\left(w_{\alpha}\right)-1} e^{-v} d v$ is the gamma function for $\eta\left(w_{c x}\right) \succ 0$. The scale parameter $(\lambda)$ could be estimated from statistical estimation methods such as a Maximum Likelihood Method by maximizing the logarithm of the likelihood function of the increment of the parameter (Van Noortwijk 2009). Assuming $J_{b}$ as the average bond strength deterioration rate associated with crack width $\left(w_{c x}\right)$, the shape function $\left(\eta\left(w_{c x}\right)\right)$ can be obtained from $\eta\left(w_{c x}\right)=\lambda J_{b}\left(w_{c x}\right)$.

Assuming $J_{L}$ as the maximum allowable limit of the bond strength deterioration, from the definition of probability of failure as discussed earlier and by integrating probability density function given in Eq. (21), the lifetime distribution of failure associated with bond strength deterioration is given by

$$
P_{f}=\operatorname{Pr}\left[J_{b}\left(w_{c x}\right) \geq J_{L}\right]=\int_{J_{b}=J_{L}}^{\infty} f_{J_{b}\left(w_{c x}\right)}\left(J_{b}\right) d J_{b}=\frac{\Gamma\left(\eta\left(w_{c x}\right), J_{L} \lambda\right)}{\Gamma\left(\eta\left(w_{c x}\right)\right)}
$$

where $\Gamma(\eta, z)=\int_{v=z}^{\infty} v^{\eta-1} e^{-v} d v$ is the incomplete gamma function for $z \geq 0$ and $\eta \succ 0$. For the case with evaluation of probability of failure in serviceability limit state such as cracking in concrete cover, similar procedure can be used where the structural deterioration relates to cover surface cracking. 
Hua-Peng Chen and Jaya Nepal

\section{Numerical example}

In this section the methodology mentioned in the preceding section is applied to a numerical example for a simply supported RC beam of span $5 \mathrm{~m}$ with minimum service life of 50 years designed to resist aggressive environment as defined by Eurocode 2 . The cross-sectional width and effective depth of beam are $b=300 \mathrm{~mm}$ and $d=560 \mathrm{~mm}$, respectively. Four rebar of a diameter 20 $\mathrm{mm}\left(D_{b}=20 \mathrm{~mm}\right)$ are provided as the tension rebar. Two bars of a diameter $16 \mathrm{~mm}\left(D_{s c}=16 \mathrm{~mm}\right)$ are provided as the compression rebar with clear cover thickness of $40 \mathrm{~mm}(C=40 \mathrm{~mm})$ and transverse reinforcement of diameter $d_{s t}=8 \mathrm{~mm}$ is provided at $70 \mathrm{~mm}$ spacing.

The compressive strength of concrete $f_{c k}=40 \mathrm{MPa}$ and the yield strength of original reinforcing steel $f_{y k}=460 \mathrm{MPa}$ with modulus of elasticity $E_{s t}=200 \mathrm{GPa}$ are adopted in this study. Material properties required for this analytical model are assumed as total crack number $n_{c}=4$, Poisson's ratio $\vartheta=0.18$, creep coefficient $\theta_{c}=2.0, i_{\text {corr }}=1 \mu \mathrm{A} / \mathrm{cm}^{2}, G_{f}=200 \mathrm{~N} / \mathrm{m}, \rho_{s}=7850 \mathrm{~kg} / \mathrm{m}^{3}$, volume ratio of corrosion product $\gamma_{v o l}=2.0$, and the corresponding molecular weight ratio $\gamma_{m o l}=0.725$. The critical and ultimate cohesive crack width have been obtained from CEB-FIP (1990) for nominal maximum aggregate size $D_{a}=20 \mathrm{~mm}$. Other parameters such as $f_{t}$ and $E_{c}$ are evaluated from Eurocode 2.

The results in Fig. 5 show the analytically predicted equivalent surface crack width $\left(w_{c x}\right)$ as a function of corrosion level $\left(X_{p}\right)$ in percentage. The predicted results are then compared with experimental investigations obtained from accelerated or natural corrosion tests in concrete (Rodriguez et al. 1994, Alonso et al. 1998, Vidal et al. 2004, Torres-Acosta et al. 2007, Gu et al. 2010, Xia et al. 2012, Coronelli et al. 2013, Khan et al. 2014, and Banba et al. 2014). It can be seen from Fig. 5 that the predicted crack width increases as reinforcement corrosion level increases, agreeing well with the referred experimental results.

The residual bond strength of confined concrete predicted by the present analytical study is plotted in Fig. 6 as function of surface crack width and compared with the published experiment data obtained from various references (Rodriguez et al. 1994, Fischer 2010, Law et al. 2011, and

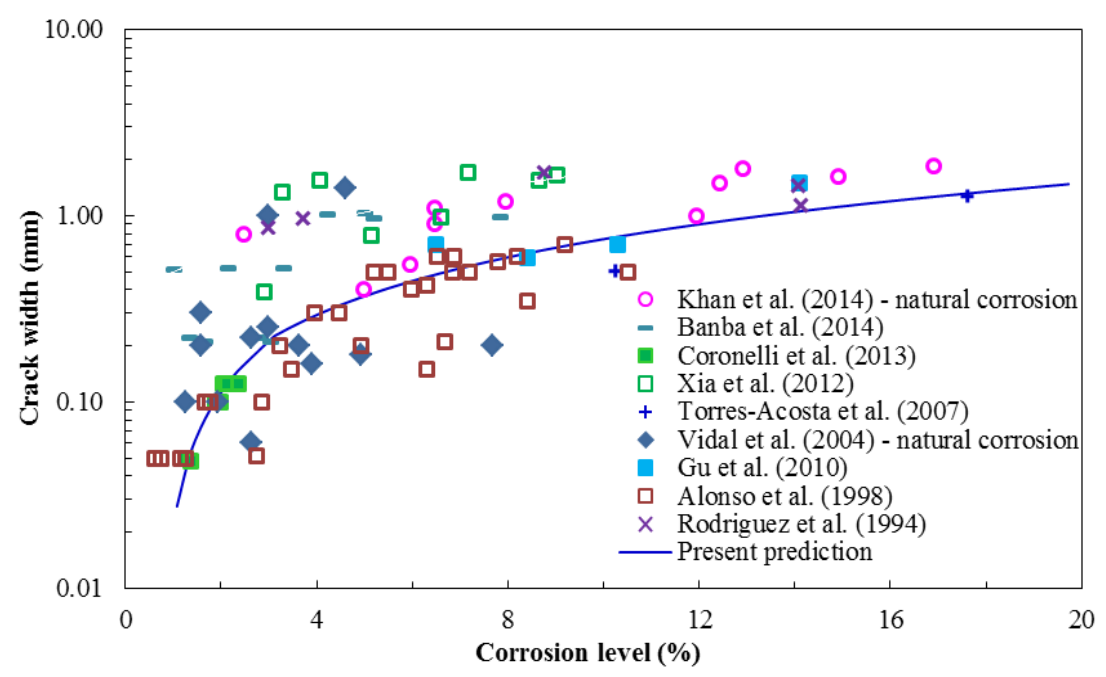

Fig. 5 Analytical prediction of crack width versus corrosion level, compared with experimental test results available from various sources 
Stochastic modelling and lifecycle performance assessment of bond strength...

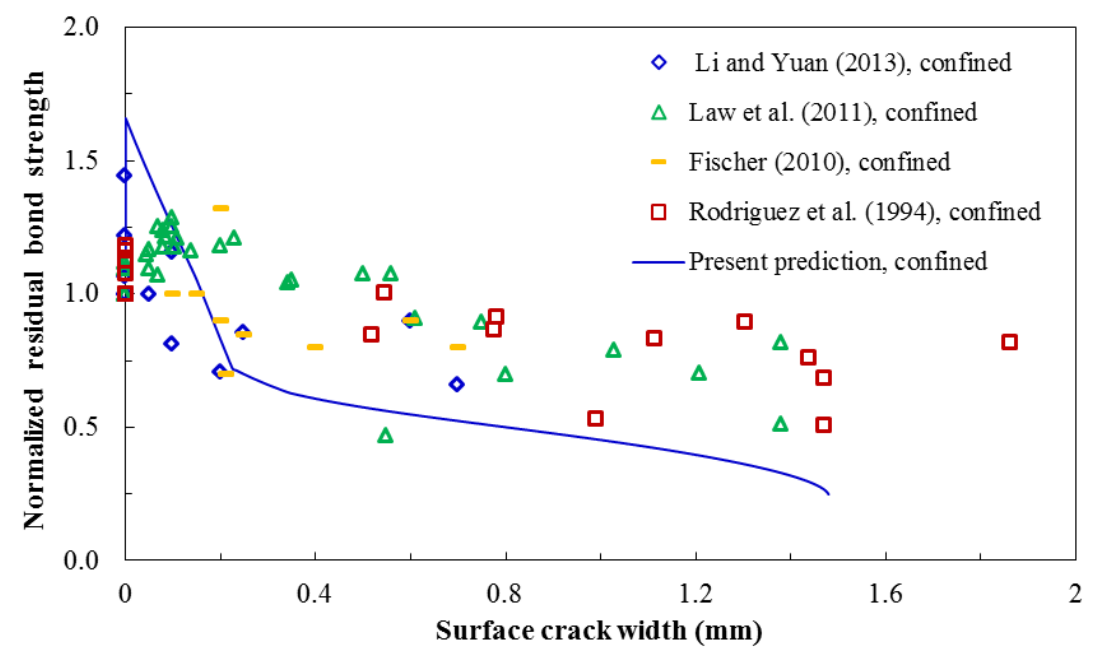

Fig. 6 Analytical prediction of normalized residual bond strength versus surface crack width for confined concrete, compared with experimental test results available from various sources

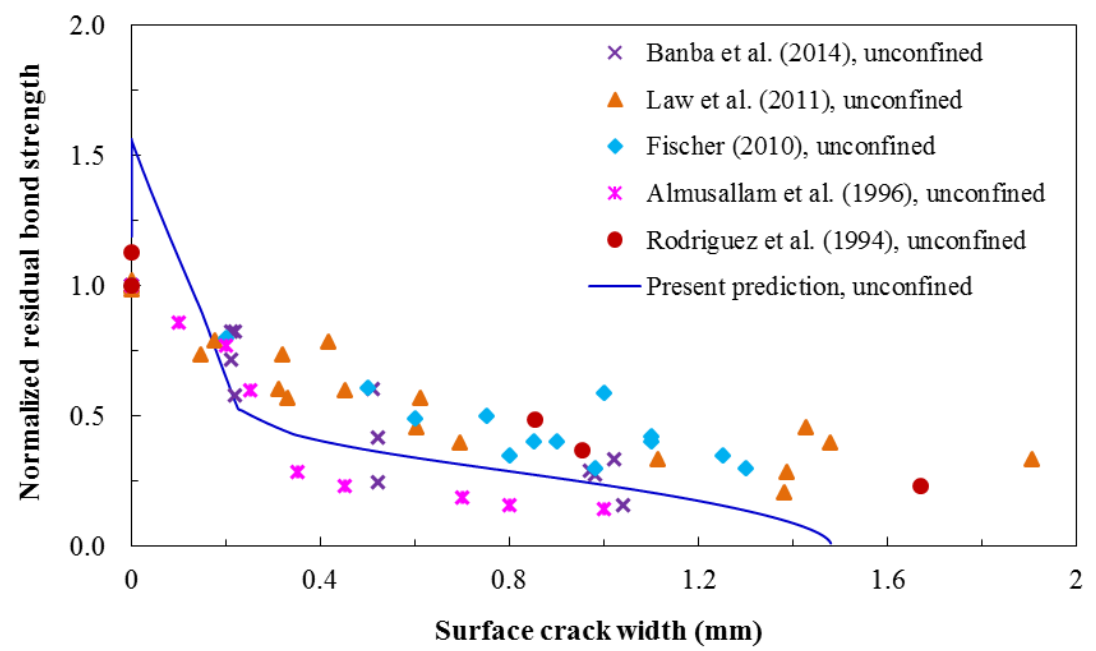

Fig. 7 Analytical prediction of normalized residual bond strength versus surface crack width for unconfined concrete, compared with experimental test results available from various sources

Li and Yuan 2013). In Fig. 6, the normalized residual bond strength is calculated by dividing the ultimate bond strength of corroded element $\left(T_{u b x}\right)$ by the ultimate bond strength of non-corroded element $\left(T_{u b o}\right)$. The ultimate bond strength of non-corroded element is evaluated from Eq. (12), where the corrosion level $\left(X_{p}\right)$, the corresponding corrosion depth $(x)$ and crack width at rebar surface $\left(w_{b x}\right)$ are taken as zero.

In Fig. 6, despite the lower value of normalized residual bond strength in predicted results at the later corrosion stage, in general the predicted trend for residual bond strength deterioration of confined concrete with respect to surface crack width agrees well with the available experimental data. The lower value of normalized residual bond strength might be due to the difference in material properties, concrete geometry and the rate of corrosion density adopted in this study, 


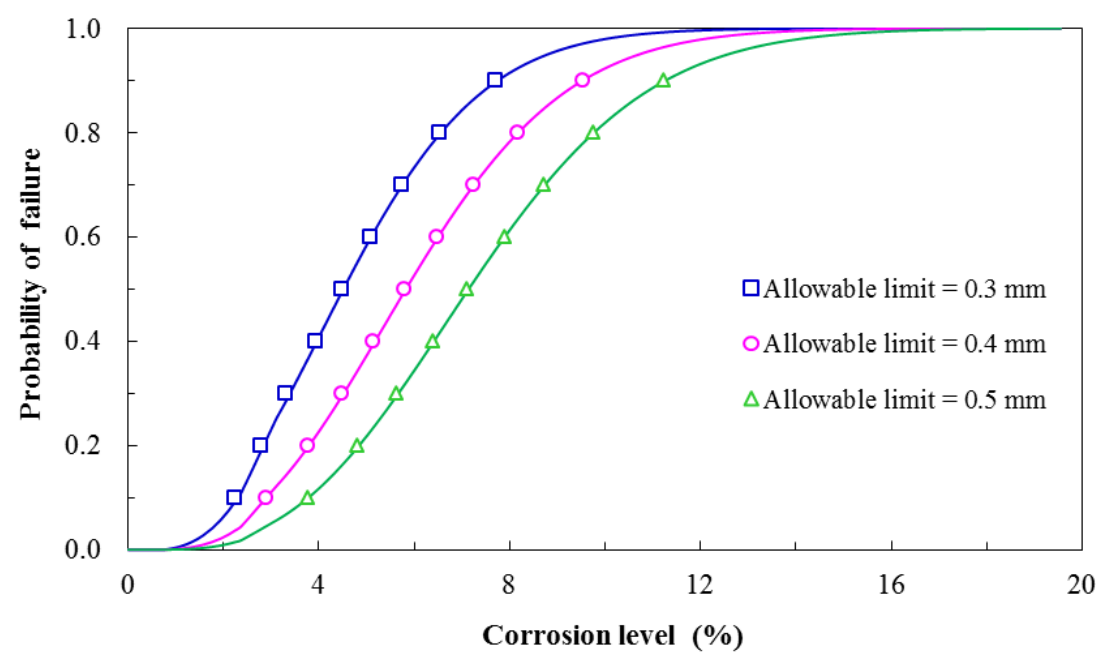

Fig. 8 Probability of failure of corroded RC structure versus corrosion level for various acceptable crack width limits

compared with the actual data for various experimental investigations. At the initial stage of surface cracking the bond strength is about $60 \%$ higher than that in the non-corroded stage. It decreases considerably with further increase in surface crack width and lost $75 \%$ of initial strength (non-corroded) stage when the surface crack width reaches about $1.5 \mathrm{~mm}$.

The results of normalized residual bond strength versus surface crack width for unconfined concrete predicted by the present analytical study are plotted in Fig. 7 and compared with the published experiment data obtained from various references (Rodriguez et al. 1994, Almusallam et al. 1996, Fischer et al. 2010, Law et al. 2011, and Banba et al. 2014). Here again, the trend of bond strength deterioration with increase in surface crack width predicted by the present study is in good agreement with the experimental investigation of the reference literatures. The residual bond strength of unconfined concrete reduces with the increase in cover surface crack width, which is similar to the case of confined concrete. But in the case of unconfined concrete residual bond strength vanishes when crack width is about $1.5 \mathrm{~mm}$ (ultimate cohesive value). This is due to the absence of transverse reinforcement (stirrups) in unconfined concrete. Hence, the results from Fig. 6 and Fig. 7 show that, at the same stage of surface crack width, unconfined concrete is more vulnerable than confined concrete.

The deterioration of structural performance in terms of surface cracking of the concrete cover is modelled as gamma process by considering the analytical results presented in Fig. 5. At first, surface crack width $\left(w_{c x}\right)$ is considered as an indicator of performance deterioration for the serviceability of the RC structure and is adopted here to replace $J_{b}$ in Eq. (22). The lifetime distribution of probability of failure $\left(P_{f}\right)$ of the corroded beam is obtained from Eq. (22) for different acceptable crack width limits, $J_{L}=0.3,0.4$ and $0.5 \mathrm{~mm}$, respectively. The results are then presented in Fig. 8 as a function of corrosion level. As expected, the probability of failure associated with cracking of the concrete cover depends on the given acceptable crack width limit, with a higher probability of failure for a lower acceptable crack width limit. The probability of failure increases steadily with progress of corrosion and reaches approximately $50 \%$ when corrosion level is approximately between $5 \%$ and $8 \%$. 
Stochastic modelling and lifecycle performance assessment of bond strength...

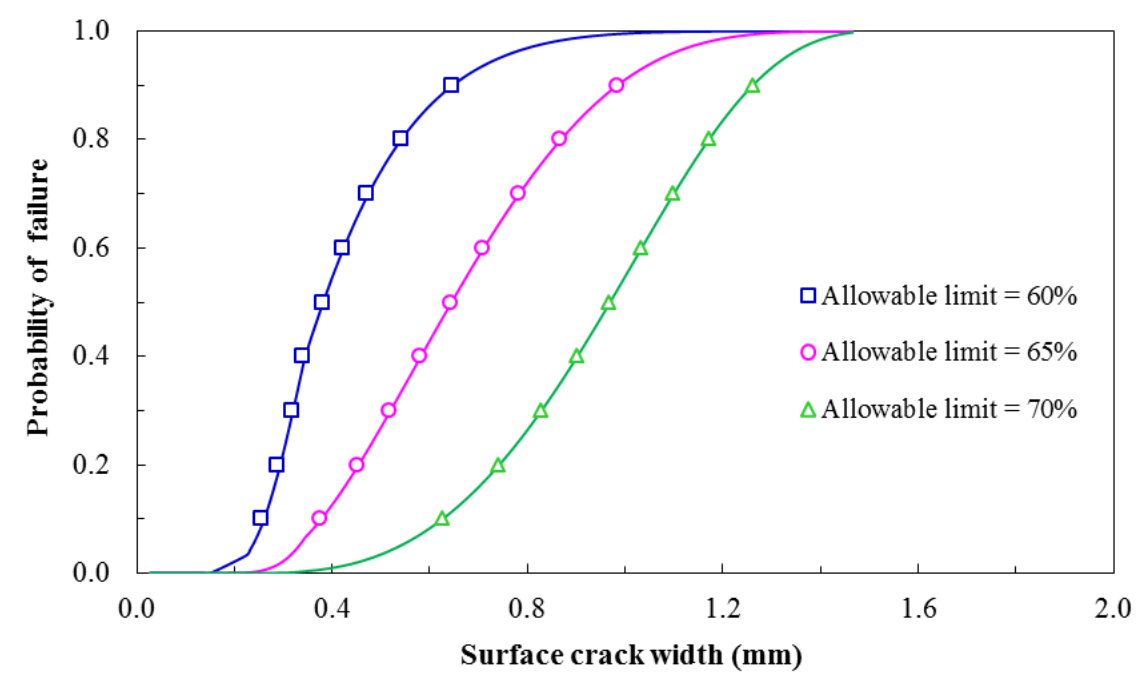

Fig. 9 Probability of failure of confined concrete versus surface crack width for various allowable bond strength deterioration limits

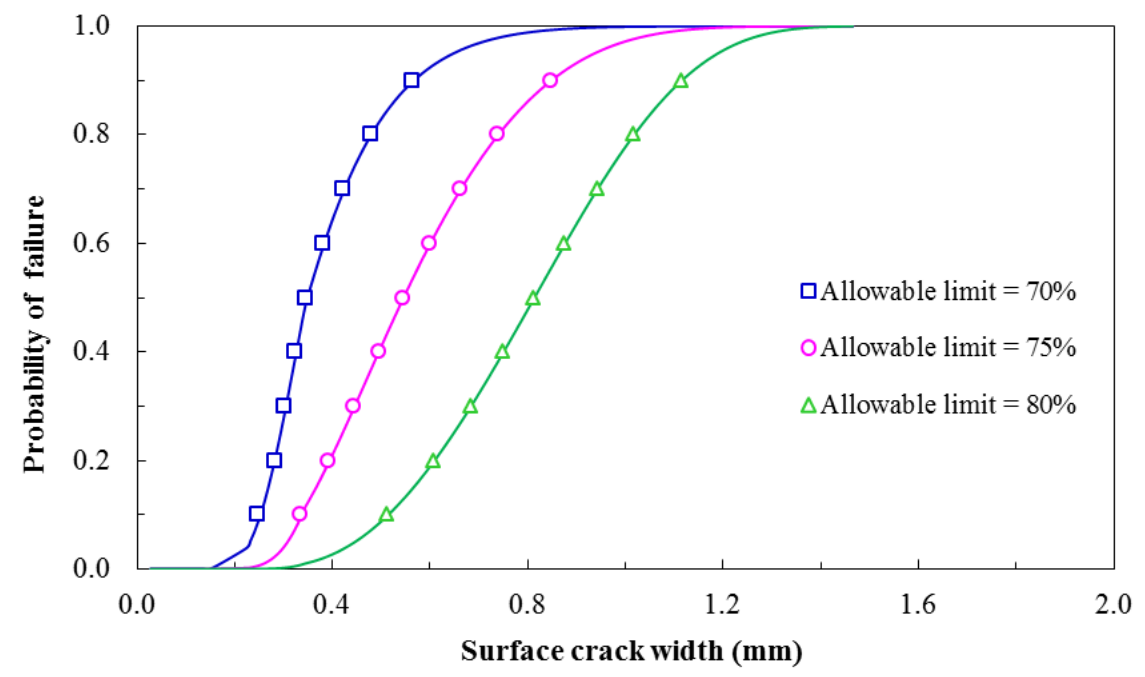

Fig. 10 Probability of failure of unconfined concrete versus surface crack width for various allowable bond strength deterioration limits

The deterioration of the structural performance associated with structural strength is now represented by bond strength degradation. Here the analytical results of bond strength deterioration in confined concrete presented in Fig. 6 is used for stochastic deterioration analysis as mentioned in Eq. (22). As shown in Fig. 6 when surface crack width is close to $0.3 \mathrm{~mm}$, the residual bond strength of confined concrete only maintains $65 \%$ of its initial (non- corroded stage) strength. This corresponds to $65 \%$ of bond strength lost compared with bond strength at the onset of surface cracking. In order to calculate the probability of failure associated with specific allowable bond strength, maximum allowable limit of bond strength deterioration is considered as $J_{L}=60 \%, 65 \%$ 
and $70 \%$, respectively. The results of probability of failure $\left(P_{f}\right)$ of the confined concrete obtained from Eq. (22) are shown in Fig. 9 for different allowable bond strength deterioration limits. Here again, the probability of failure associated with bond strength deterioration depends on the given allowable strength deterioration limit. For the same stage of surface crack width the probability of failure is lower for the higher allowable deterioration limit.

Similarly, by considering the analytical results obtained from Fig. 7 for the unconfined concrete, the results for probability of failure for unconfined concrete have been presented in Fig. 10. As shown in Fig. 7, when surface crack width is about $0.3 \mathrm{~mm}$, the residual bond strength of the unconfined concrete has lost approximately $70 \%$ of the original strength, at the onset of surface cracking. Here similarly, maximum allowable limit of bond strength deterioration is considered as: $J_{L}=70 \%, 75 \%$ and $80 \%$, respectively. The probability of failure associated with the bond deterioration for different allowable limit increases steadily with increase in surface crack width. As shown in Fig. 9, here again, unconfined concrete shows the highest probability of failure in lowest allowable limit of deterioration and lowest probability of failure in the highest allowable limit.

From the results of probability of failure shown in Fig. 9 and Fig. 10, it is clear that the unconfined concrete has considerably higher probability of failure than the confined concrete when the same predefined allowable limit and concrete cover crack width are considered.

\section{Conclusions}

This paper presents a new approach for evaluating the life cycle performance of corrosion affected RC structures. At first, the bond strength deterioration caused by corroded reinforcement and crack growth in concrete cover is evaluated by analytical investigations. The analytical results for bond strength deterioration are then validated by experimental data available. Growth in surface crack width with increase in reinforcement corrosion is discussed and its effect on bond strength deterioration is analyzed. The behavior of confined and unconfined concrete with increase in surface crack width is also investigated. Furthermore, by using the stochastic model on the verified analytical results, the probability of structural failure associated with the surface crack width and bond strength deterioration over the lifecycle of corrosion affected RC structures is evaluated. The application of the proposed approach is illustrated with the numerical example.

On the basis of the results obtained from the numerical example, following conclusions are drawn: a) The proposed approach can reliably predict the crack growth and residual bond strength deterioration of the corroded RC structures; b) Bond strength decreases with increase in surface crack width. At the same stage of surface crack width bond strength is reduced more in unconfined concrete than in confined concrete. When surface crack width reaches its ultimate cohesive value, the confined concrete still possesses about $25 \%$ of its initial strength whereas no residual bond strength is observed in the unconfined concrete; c) The probability of failure of corrosion affected RC structures during their life cycle depends not only on the predefined allowable limit of their deterioration but also on the confinement of concrete; d) Structural reliability decreases with increase of surface cracking and its corresponding bond strength deterioration. Thus, the proposed approach is capable of assessing the life cycle performance of concrete structures affected by reinforcement corrosion. 
Stochastic modelling and lifecycle performance assessment of bond strength...

\section{References}

Almusallam, A.A., Al-Ghantani, A.S., Aziz, A.R. and Rasheeduzzafar. (1996), "Effect of reinforcement corrosion on bond strength", Construct. Build. Mater., 10(2), 123-129.

Alonso, C., Andrade, C., Rodriguez, J. and Diez, J.M. (1998), "Factors controlling cracking of concrete affected by reinforcement corrosion”, Mater. Struct., 31(7), 435-441.

Al-Sulaimani, G.J., Kaleemullah, M., Basanbul, I.A. and Rasheeduzzafar. (1990), "Influence of corrosion and cracking on bond behaviour and strength of reinforced concrete members", ACI Struct. J., 87(2), 220231.

Auyeung, Y.B., Balaguru, P. and Chung, L. (2000), "Bond behaviour of corroded reinforcement bars", ACI Mater. J., 97(2), 214-220.

Banba, S., Abe, T., Nagaoka, K. and Murakami, Y. (2014), "Evaluation method for bond-splitting behavior of reinforced concrete with corrosion based on confinement stress of concrete against corrosion expansion", J. Adv. Concrete Tech., 12(1), 7-23.

Bhargava, K., Ghosh, A.K., Mori, Y. and Ramanujam, S. (2007a), "Ultimate flexural and shear capacity of concrete beams with corroded reinforcement", Struct. Eng. Mech., 27(3), 347-363.

Bhargava, K., Ghosh, A.K., Mori, Y. and Ramanujam, S. (2007b), "Corrosion-induced bond strength degradation in reinforced concrete- analytical and empirical models", Nucl. Eng. Des., 237(11), 11401157.

Cairns J., Du, Y. and Law, D. (2006), "Residual bond strength of corroded plain round bars”, Mag. Concrete Res., 58(4), 221- 231.

Cairns, J. and Abdullah, R.B. (1996), "Bond strength of black and epoxy-coated reinforcement-a theoretical approach", ACI Mater. J., 93(4), 362-369.

CEB-FIP (1990), CEB-FIP Model Code 1990, Comité Euro-International du Béton (CEB), Thomas Telford, London, UK.

Chen, H.P. and Alani, A.M. (2012), "Reliability and optimised maintenance for sea defences", Proc. ICE: Marit. Eng. 165(2), 51-64.

Chen, H.P. and Alani, A.M. (2013), "Optimized maintenance strategy for concrete structures affected by cracking due to reinforcement corrosion", ACI Struct. J., 110(2), 229-238.

Chen, H.P. and Bicanic, N. (2010), "Identification of structural damage in buildings using iterative procedure and regularisation method", Eng.Comput. 27(8), 930-950.

Chen, H.P. and Xiao, N. (2012), "Analytical solutions for corrosion-induced cohesive concrete cracking", J.Appl.Math. Article ID 769132.

CD. H, H.P. and Xiao, N. (2014), "Reliability analyses and performance assessment of corroded reinforced concrete structures", Struct. Mech. Eng., 53(6), 183-1200.

Coronelli, D. (2002), "Corrosion cracking and bond strength modelling for corroded bars in reinforced concrete”, ACI Struct. J., 99(3), 267-276.

Coronelli, D. and Gambarova, G. (2000), "A mechanical model for bond strength of corroded reinforcement in concrete", Proceedings of the 14th Engineering Mechanics Conference, Austin, Texas.

Coronelli, D., Hanjari, K. and Lundgren, K. (2013), "Severely corroded RC with cover cracking", J. Struct. Eng., ASCE, 139(2), 221-232.

Eurocode 2 (2004), Design of Concrete Structure, European comitee for standardization, Brussels, Belgium.

Fischer, C. (2010), "Experimental investigations on the effect of corrosion on bond of deformed bars", 8th fib PhD Symposium, Kgs, Lyngby, Denmark.

(P) n, Y., Luan, H. and Wang, D. (2014), "A study of deterioration of reinforced concrete beams under various forms of simulated acid rain attack in the laboratory", Struct. Mech. Eng., 52(1), 35-49.

Frangopol, D.M., Kong, J.S. and Gharaibeh, E.S. (2001), "Reliability-based life-cycle management of highway bridges", J. Comput. Civil Eng., ASCE, 15(1), 27-34.

Giuriani, E., Plizzari, G. and Schumm, C. (1991), "Role of stirrups and residual tensile strength of cracked concrete on bond", J. Struct. Eng., ASCE, 117(1), 1-18. 


\section{Hua-Peng Chen and Jaya Nepal}

Gu, X., Zhang, W., Shang, D. and Wang, X. (2010), "Flexural behaviour of corroded reinforced concrete beams", Earth and Space 2010, ASCE, 3545-3552.

Hillerborg, A., Modeer, M. and Petersson, P.E. (1976), "Analysis of crack formation and crack growth in concrete by means of fracture mechanics and finite elements", Cement Concrete Res., 6(6), 773-782.

Huang, T.L. and Chen, H.P. (2013), "Symptom-based reliability analysis and remaining service life prediction of deteriorating RC structures", Key Eng. Mater., 569, 151-158.

Khan, I., Francois, R. and Castel, A. (2014), "Prediction of reinforcement corrosion using corrosion induced cracks width in corroded reinforced concrete beams", Cement Concrete Res., 56, 84-96.

Law, D.W., Tang, D., Molyneaux, T.K.C. and Gravina, R. (2011), "Impact of crack width on bond: confined and unconfined rebar", Mater. Struct., 44(7), 1287-1296.

Li, F. and Yuan, Y. (2013), "Effects of corrosion on bond behavior between steel strand and concrete", Construct. Build. Mater., 38, 413-422.

Lundgren, K. (2002), "Modelling the effect of corrosion on bond in reinforced concrete", Mag. Concrete Res., 54(3), 165-173.

Nepal, J., Chen, H.P. and Alani, A.M. (2013), “Analytical modelling of bond strength degradation due to reinforcement corrosion”, Key Eng. Mater., 569, 1060-1067.

Nepal, J. and Chen, H.P. (2014), "Evaluation of residual strength of corrosion damaged reinforced concrete structures", 4th International Symposium on Life-Cycle Civil Engineering, Tokyo, Japan.

Pantazopoulou, S. and Papoulia, K. (2001), "Modeling cover-cracking due to reinforcement corrosion in RC structures", J. Eng. Mech., ASCE, 127(4), 342-351.

Rodriguez, J., Ortega, L.M. and Casal, J. (1994), "Corrosion of reinforcing bars and service life of reinforced concrete structures: corrosion and bond deterioration", Proceedings of International Conference on Concrete across Borders, Odense, Denmark.

Shetty, A., Venkataramana, K. and Narayan K.S. B. (2014), "Flexural bond strength behaviour in OPC concrete of NBS beam for various corrosion levels", Struct. Mech. Eng., 49(1), 81-93.

Tee, K.F., Khan, L.R. and Chen, H.P., (2013), "Probabilistic failure analysis of underground flexible pipes", Struct. Mech. Eng., 47(2), 167-183.

Torres-Acosta, A.A., Navarro-Gutierreza, S. and Teran-Guillen J. (2007), "Residual flexure capacity of corroded reinforced concrete beams", Eng. Struct., 29(6), 1145-1152.

Val, D.V., Stewart, M.G. and Melchers, R.E. (1998), "Effect of reinforcement corrosion on reliability of highway bridges”, Eng. Struct., 20(11), 1010-1019.

Van Noortwijk, J.M. (2009), "A survey of the application of gamma processes in maintenance", Reliab. Eng. Syst. Saf., 94(1), 2-21.

Van Noortwijk, J.M. and Frangopol, D.M. (2004), "Two probabilistic life-cycle maintenance models for deteriorating civil infrastructures", Probab. Eng. Mech., 19(4), 345-359.

Vidal, T., Castel, A. and Francois, R. (2004), "Analyzing crack width to predict corrosion in reinforced concrete", Cement Concrete Res., 34(1), 165-174.

Wang, X.H. and Liu, X.L. (2004), "Modelling effects of corrosion on cover cracking and bond in reinforced concrete", Mag. Concrete Res., 56(4), 191-199.

Xia, J., Jin, W.L. and Li, L.Y. (2012), "Effect of chloride-induced reinforcing steel corrosion on the flexural strength of reinforced concrete beams", Mag. Concrete Res., 64(6), 471-485.

Zhang, R., Castel, A. and Francois, R. (2010), "Concrete cover cracking with reinforcement corrosion of RC beam during chloride-induced corrosion process", Cement Concrete Res., 40(3), 415-425.

Zhao, Y., Lin, H., Wu, K. and Jin, W. (2014), "Bond behaviour of normal/recycled concrete and corroded steel bars", Construct. Build. Mater., 48, 348-359. 